\title{
Vitamin K1 Inhibition of Renal Crystal Formation through Matrix Gla Protein in the Kidney
}

\author{
Yang Lia, d,e Xiuli Lu ${ }^{a}$ Baoyu Yang a Jing Mao ${ }^{a}$ Shan Jiang ${ }^{a}$ \\ Daojun Yu ${ }^{d, e}$ Jichuan Pan ${ }^{b}, d, e$ Tiange Cai ${ }^{a}$ Takahiro Yasuic, ${ }^{c}$ \\ Bing Gaob, d, e
}

aDepartment of Biochemistry and Cell Biology, School of Life Sciences, Liaoning University, Shenyang, China; ${ }^{b}$ Department of Cell Biology and Genetics, Shenyang Medical College, Shenyang, China; ' ${ }^{\circ}$ Department of Nephro-Urology, Nagoya City University Graduate School of Medical Sciences, Nagoya, Japan; dChina-Japan Kidney Stone Research Center,

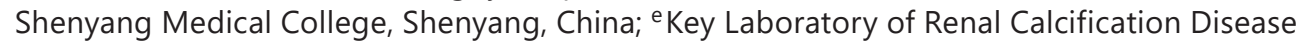
Prevention and Treatment, Shenyang, China

\section{Keywords}

Nephrolithiasis · Vitamin K1 · Matrix Gla protein · Calcification

\begin{abstract}
Background and Objectives: Vitamin K (VK) plays a major role in modifying the binding of calcium in bones and blood vessels. Understanding the effect of VK on crystal formation in the kidney would contribute to advancing the treatment and prevention of kidney stones. Methods: Rats were treated with vitamin K1 (VK1) for 8 weeks. VK1 levels were detected and crystal formation were observed. HK2 cells were exposed to calcium oxalate monohydrate crystals. Apoptosis and cell viability were detected. Crystal deposition was analyzed using atomic absorption assay. The adenovirus vectors expressing matrix Gla protein (MGP) and siMGP were constructed to elucidate the effect and mechanism of VK1 on crystal formation. MGP expression in vivo and in vitro was analyzed by Western blot. The mRNA levels of monocyte chemoattractant protein-1 (MCP-1) and collagen I was measured by semiquantitative RT-PCR. Results: The concentrations of VK1 in whole blood and kidney tissues rose under treatment with VK1. Crystal formation was inhibited from the second to the 6th week, the frequency and quality of crystal formation decreased significantly, and the location of crystal formation was limited to a greater extent in the rats treated by VK1 compared to the control group. Warfarin treatment in the crystals-exposed HK2 cells significantly increased the number of crystals adhering to cells and the number of apoptotic cells and reduced cell viability.
\end{abstract}

Y. Li and X. Lu contributed equally to this work. 


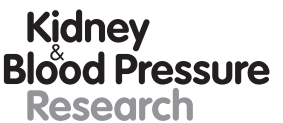

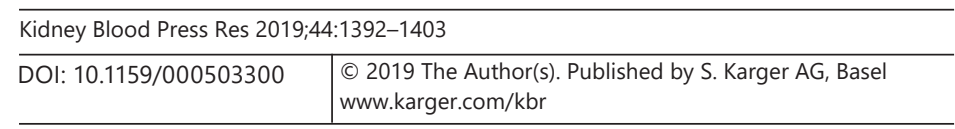

Li et al.: Vitamin K1 Inhibits Renal Crystal Formation

VK1 treatment reversed warfarin's above influence. VK1 inhibited the upregulations of MCP-1 and collagen I in kidney tissues under crystal load. VK1 treatment increased MGP expression in vivo and in vitro, and MGP is necessary for VK1 to play a role in crystal deposition in cells. Conclusions: VK1 treatment can inhibit the formation of renal crystals in vivo. VK1 increases MGP expression and functions through MGP to reduce crystal deposition in cells and provide cell protection. Our findings suggest that VK1 treatment could be a potential strategy for the treatment and prevention of nephrolithiasis.

(C) 2019 The Author(s)

Published by S. Karger AG, Basel

\section{Introduction}

Nephrolithiasis has a lifetime incidence of up to $2-5 \%$ of the population in Asia, $5-9 \%$ in Europe, and 8-15\% in North America [1, 2]. Once stones have formed, recurrence rates are $40 \%$ at 3 years and $74 \%$ at 10 years $[2,3]$. Calcium oxalate is the most common type, accounting for $70-80 \%$ of the nephrolithiasis population [4]. There has been increasing evidence that nephrolithiasis is a systemic disorder that leads to end-stage renal disease [5, 6]. However, the exact mechanism of stone formation is still unclear so far, resulting in a lack of effective treatment and preventive measures.

Stone formation is a complex biological process in the kidney, similar to the mechanism of calcification in blood vessels and bones. Hydroxyapatite was observed to deposit in both atherosclerotic plaques and Randall's plaques. Some bone-related proteins such as matrix Gla protein (MGP) and osteopontin have been reported to be associated with these calcifications [7-9]. Recently, increasing evidence has shown that vitamin $\mathrm{K}(\mathrm{VK})$ is useful in preventing vascular calcification $[10,11]$. VK deficiency results in cardiovascular calcification, whereas a high VKintake can improve diseases that result from vascular calcification [12,13]. However, whether VK plays a similar role in inhibiting crystal formation in the kidney is still unclear.

In the present study, we observed crystal formation in rat models, performed apoptosis assay, cell viability assay, Western blot analysis, and atomic absorption assay. We constructed adenovirus vectors expressing MGP and siMGP to establish the effect and mechanism of vitamin K1 (VK1) in preventing crystal formation in vitro. We found, for the first time, that intake of VK1 inhibits renal crystal formation by reducing crystal deposition in cells, increasing MGP expression, and providing cell protection from apoptosis and injury. Moreover, VK1 also protects the kidney from inflammation and fibrosis. The function of VK1 is achieved through MGPs. Our findings provide a potential strategy utilizing VK1 for treatment and prevention of nephrolithiasis.

\section{Methods}

\section{Animal Models}

Male Sprague-Dawley rats were divided into two groups, the VK1 group $(n=25)$ and the control group $(n=25)$. Both groups were induced by $0.75 \%$ ethylene glycol (EG) in drinking water for up to 8 weeks. Intraperitoneal injection of $0.77 \mathrm{mg} / 100 \mathrm{~g} \mathrm{VK} 1$ was performed in the VK1 group, and $0.9 \%$ saline was injected in the control group every day [14, 15]. Rats were killed at $0,2,4,6$, and 8 weeks.

\section{Detection of VK1}

The concentrations of VK1 in whole blood and kidney tissues were detected. Whole blood was collected with a sterile tube containing anticoagulant. One gram of kidney tissues in $9 \mathrm{~g}$ 


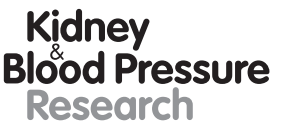

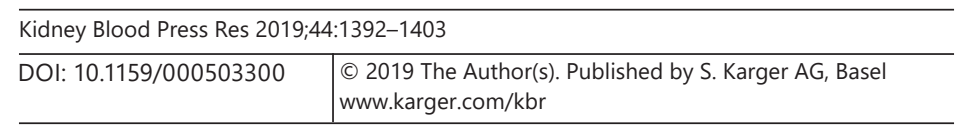

Li et al.: Vitamin K1 Inhibits Renal Crystal Formation

of PBS was adequately homogenized, followed by centrifugation for $20 \mathrm{~min}$ at 3,000 rpm. The supernatant was collected carefully and maintained at $-80^{\circ} \mathrm{C}$ for storage. The levels of VK1 were detected with a rat VK1 ELISA kit (mm-0525R1, Meimian, China) according to the manufacturer's specification.

\section{Immunostaining}

Five-micrometer-thick paraffin sections were prepared from $4 \%$ paraformaldehydefixed paraffin-embedded rat kidney. Sections were stained with hematoxylin and eosin. The tissue and crystals were observed using a light microscope and a polarizing microscope.

\section{Cell Culture}

The HK2 cells (American Type Culture Collection) were cultured in Dulbecco's modified Eagle's medium (DMEM) supplemented with $10 \%$ fetal calf serum at $37^{\circ} \mathrm{C}$ in a $5 \% \mathrm{CO}_{2}$ atmosphere. Cells were exposed for $3,6,12,24$, and $48 \mathrm{~h}$ to $100 \mu \mathrm{g} / \mathrm{mL}$ calcium oxalate monohydrate (COM) crystals, $100 \mu \mathrm{M}$ VK1, and $1 \mathrm{~m}$ warfarin in the DMEM, respectively.

\section{Apoptosis Assay}

Apoptosis was detected by 4',6-diamidino-2-phenylindole (DAPI) staining and a TUNEL assay using a TUNEL FITC Apoptosis Detection Kit (A111, Vazyme, China). Cells were plated into six-well plates and treated with $100 \mu \mathrm{g} / \mathrm{mL}$ COM crystals, $100 \mu \mathrm{M} \mathrm{VK} 1$, and $1 \mathrm{M}$ warfarin for $48 \mathrm{~h}$. The cells were fixed with $4 \%$ polyoxymethylene for $10 \mathrm{~min}$, incubated in proteinase $\mathrm{K}(20 \mu \mathrm{g} / \mathrm{mL})$ for $5 \mathrm{~min}$, and labeled with FITC-12-dUTP according strictly to the manufacturer's instruction. Finally, the coverslips were equilibrated in PBS, followed by $200 \mu \mathrm{L}$ DAPI $(5 \mathrm{mg} / \mathrm{mL}$ ) staining solution being added to the coverslips, and incubated for $5 \mathrm{~min}$ at room temperature. The coverslips were viewed using a fluorescence microscope.

\section{Cell Viability Assay}

Cell viability was determined using 3-(4,5-dimethylthiazol-2-yl)-2,5-diphenyltetrazolium bromide (MTT) assay. Cells were plated in 96-well plates with 5,000 cells/well followed by incubation with $100 \mu \mathrm{g} / \mathrm{mL}$ COM crystal, $100 \mu \mathrm{M}$ VK1, and $1 \mathrm{M}$ warfarin for $48 \mathrm{~h}$. After incubation, fresh medium containing $20 \mu \mathrm{L}$ of $5 \mathrm{mg} / \mathrm{mL}$ MTT solution was added. After $4 \mathrm{~h}$, the medium was replaced with $150 \mu \mathrm{L}$ of formazan. Absorbance at $490 \mathrm{~nm}$ was measured using a microplate reader.

\section{Adenovirus Vector Construction and Recombinant Adenovirus Production}

PCR amplified the entire coding sequence of human MGP cDNA. A Kozak sequence was introduced in the sense primer. The stop codon was deleted in the antisense primer. The amplified MGP cDNA was cloned into an adenovirus vector pAdeno-mCMV-3flag-IRES2-EGFP (Obio Technology, Shanghai, China). The siRNA targeting MGP was designed and cloned into an adenovirus vector pDKD-CMV-eGFP-U6-shRNA (Obio Technology). The DNA sequencing was performed to verify the sequence of insertion with $100 \%$ identity. Then, the constructed recombinant adenovirus vectors pAdeno-MCMV-3flag-IRES2-EGFP-MGP and pDKD-CMVEGFP-U6-shMGP were cotransfected into 293T cells. Recombinant adenovirus was harvested after 3 days, followed by amplification and purification using the AdMax ${ }^{\mathrm{TM}}$ system (Microbix, Canada). Finally, the concentrated adenovirus-expressing MGP and siMGP solution was obtained with a final titer of $2 \times 10^{11}$ and $1.5 \times 10^{11} \mathrm{PFU} / \mathrm{mL}$, respectively.

\section{Semiquantitative Real-Time PCR}

Total RNA was extracted from $50 \mathrm{mg}$ rat kidney tissues with $1 \mathrm{~mL}$ RNA isolator (Cat. R401-01, Vazyme). The RNA concentration was measured spectrophotometrically at $260 \mathrm{~nm}$. 


\section{Kidney \\ Blood Pressure \\ Research}

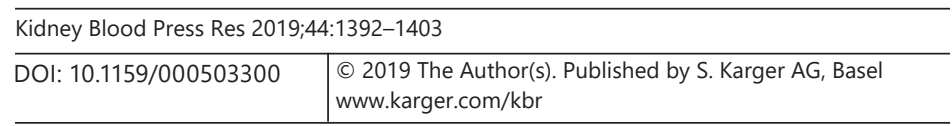

Li et al.: Vitamin K1 Inhibits Renal Crystal Formation

One microgram of total RNA was reversed into cDNA using HiScript II Q RT SupeMix (Cat. R222-01, Vazyme). Twenty microliters of PCR reaction was performed with $2 \times$ Phanta Master Mix (Cat. P511-AA, Vazyme) as follows: $95^{\circ} \mathrm{C}$ for $3 \mathrm{~min}$ followed by 35 cycles: $95^{\circ} \mathrm{C}$ for $30 \mathrm{~s}$, $59^{\circ} \mathrm{C}$ for $30 \mathrm{~s}$, and $72^{\circ} \mathrm{C}$ for $40 \mathrm{~s}$. The final extension was at $72^{\circ} \mathrm{C}$ for $10 \mathrm{~min}$. Glyceraldehyde 3 -phosphate dehydrogenase gene (GAPDH) was considered an endogenous control to normalize the variations of different samples. The primers were as follows: monocyte chemoattractant protein-1 (MCP-1) sense: 5'-GTT GTT CAC AGT TGC CT-3'; MCP-1 antisense: $5^{\prime}$-CTC TGT CAT ACT GGT CAC TTC TAC-3'; collagen I sense: $5^{\prime}$-GGG TCT AGA CAT GTT CAG CTT TGT G-3'; collagen I antisense: 5'-ACC CTT AGG CCA TTG TGT ATG C-3'; GAPDH sense: 5'-TGC TGA GTA TGT CGT GGA GTC TA; GAPDH antisense: $5^{\prime}$-AGT GGG AGT TGC TGT TGA AAT C-3'.

\section{Western Blot Analysis}

Protein was isolated from the culture cells and kidney tissues by homogenization in RIPA buffer (Solarbio) with protease inhibitors. Total cell lysates $(50 \mu \mathrm{g})$ were resolved on $10 \%$ SDS-PAGE gel and then transferred onto immobilon-p transfer membrane (Millipore, Billerica, MA, USA). Membranes were blocked using 5\% nonfat milk/TBS for 60 min and incubated overnight at $4{ }^{\circ} \mathrm{C}$, with each primary antibody being diluted at 1:500-1:1,000. After washing, membranes were incubated for $1 \mathrm{~h}$ with a peroxidase-labeled secondary antibody $(1: 2,000 ;$ ABclonal, Cat. No. AS014) at room temperature. After rewashing, bands were visualized using peroxidase-linked ECL Western blot detection reagents and the associated analysis system (Tanon). Primary antibodies consisted of rabbit anti-actin, purchased from Sigma-Aldrich (Cat. No. A2066) and rabbit polyclonal anti-MGP, purchased from OriGene (Cat. No. TA339184); beta-actin antibody was used to confirm equal protein loading among samples. All experiments were repeated in triplicate.

\section{Atomic Absorption Assay}

Atomic absorption was performed to assess the effect of calcium oxalate crystal adhesion to cells. Briefly, COM crystals were treated with ultrasound for $15 \mathrm{~min}$ to obtain uniform crystal components and suspended in DMEM. The cells were exposed to $100 \mu \mathrm{g} / \mathrm{mL} \mathrm{COM}$ crystals for $5 \mathrm{~min}$. The nonadherent crystals were removed by rapidly washing the plate three times with PBS solution. The COM crystals that adhered to cells were lysed with $5 \mathrm{~mL}$ of $6 \mathrm{M}$ $\mathrm{HCl}$ for $24 \mathrm{~h}$ and completely harvested. Normalizing quantitative analysis of the COM crystals on the cells was conducted by measuring the calcium concentration of the supernatants by atomic absorption analysis.

\section{Statistical Analysis}

Statistical analysis was carried out using the GraphPad software (San Diego, CA, USA). Statistical comparisons were analyzed by two-way analysis of variance with Dunnett's post test. A $p$ value $\leq 0.05$ was considered significant.

\section{Results}

VK1 Inhibited Crystal Formation in vivo

To understand the effect of VK1 on crystal formation in the kidney, a rat model of crystal formation was induced by $0.75 \%$ EG. The concentrations of VK1 both in whole blood and kidney tissues were upregulated in the group treated with VK1 compared to those without VK1 treatment (Fig. 1A, B). Crystals were found initially, at the second week, in $20 \%$ of the control group rats by treatment of $0.75 \%$ EG using polarizing microscopy (Fig. 1C), whereas it was not found until the 6 th week in $20 \%$ of the VK1 group rats by treatment of $0.75 \%$ EG 
A

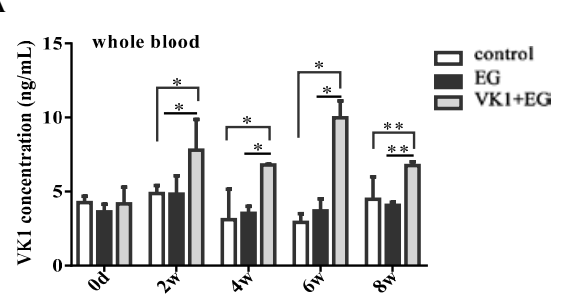

C
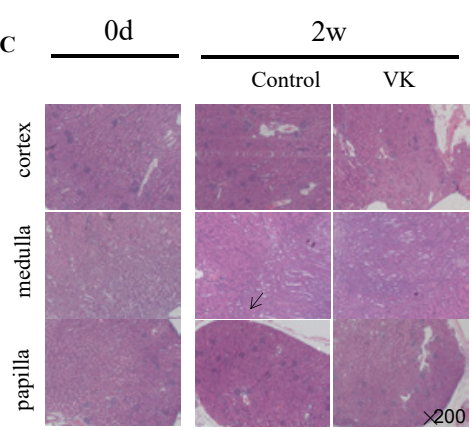

B
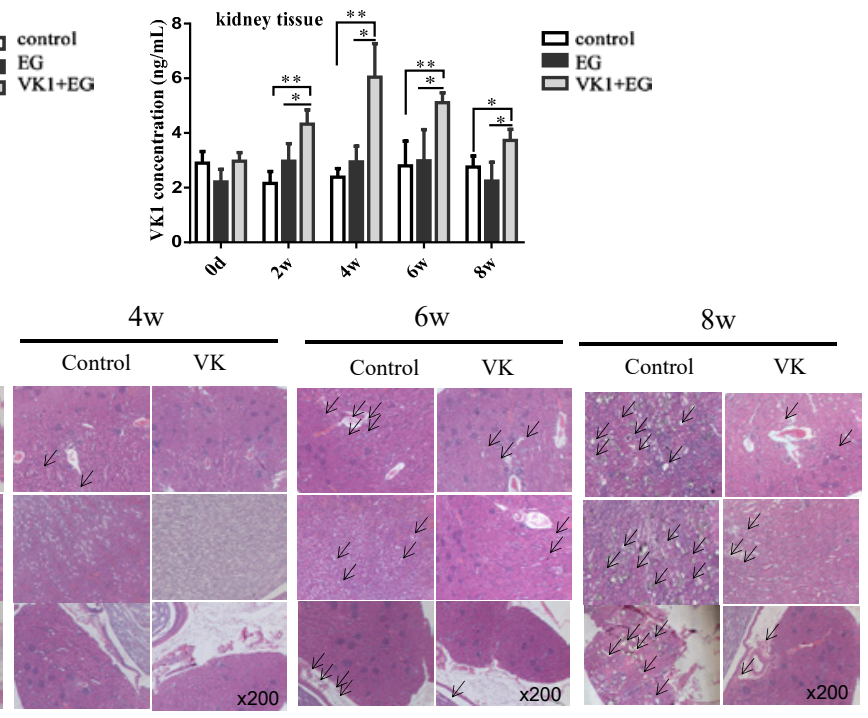

Fig. 1. Histological observation of the rat kidney. The concentrations of VK1 in whole blood (A) and kidney tissues (B) were detected with an ELISA kit. Sections were stained with hematoxylin and eosin (C). The control group was treated with $0.75 \%$ EG and the VK1 group with $0.75 \%$ EG and VK1 from day 0 to 8 weeks. Crystals were observed using a polarizing microscope. Arrows point to the formed crystals. Magnification: $\times 200 . * p<0.05,{ }^{* *} p<0.01$. EG, ethylene glycol; VK1, vitamin K1.

Table 1. Comparison of the frequency of crystal formation in rat kidneys between the VK1 and the control group

\begin{tabular}{|c|c|c|c|c|}
\hline & \multicolumn{2}{|c|}{ Crystal formation } & \multirow[t]{2}{*}{$\chi^{2}$} & \multirow[t]{2}{*}{$p$ value } \\
\hline & control & VK1 & & \\
\hline 2nd week & $1 / 5$ & $0 / 5$ & 1.611 & 0.204 \\
\hline 4th week & $3 / 5$ & $0 / 5$ & 5.786 & $0.016^{*}$ \\
\hline 6th week & $1 / 5$ & $1 / 5$ & 0 & 1 \\
\hline 8th week & $4 / 5$ & $2 / 5$ & 1.667 & 0.197 \\
\hline
\end{tabular}

VK1, vitamin $\mathrm{K} 1{ }^{*} p<0.05$

and VK1. There was a significantly lower frequency of crystals formed in the VK1 group than in the control group in the 4th week $(p=0.016)$ (Table 1). Also, crystals were observed to form sparsely in renal medulla and papilla in the VK1 group after treatment for 6 weeks, whereas crystals formed widely in renal cortex, medulla, and papilla in the control group (Fig. 1C; Table 2). The quality of crystal formation decreased significantly in the VK1 group compared to the control group $(p<0.05)$ (Table 2). These results suggest that the VK1 treatment inhibited crystal formation in rat kidneys.

\section{VK1 Protected the Kidneys from Inflammation and Fibrosis}

To clarify the effects of VK1 on inflammation activation and fibrosis by crystal load, we detected MCP- 1 and collagen I by semiquantitative real-time PCR. MCP- 1 is a potent agonist for mononuclear leukocytes and recruits monocytes to sites of inflammation in various path- 


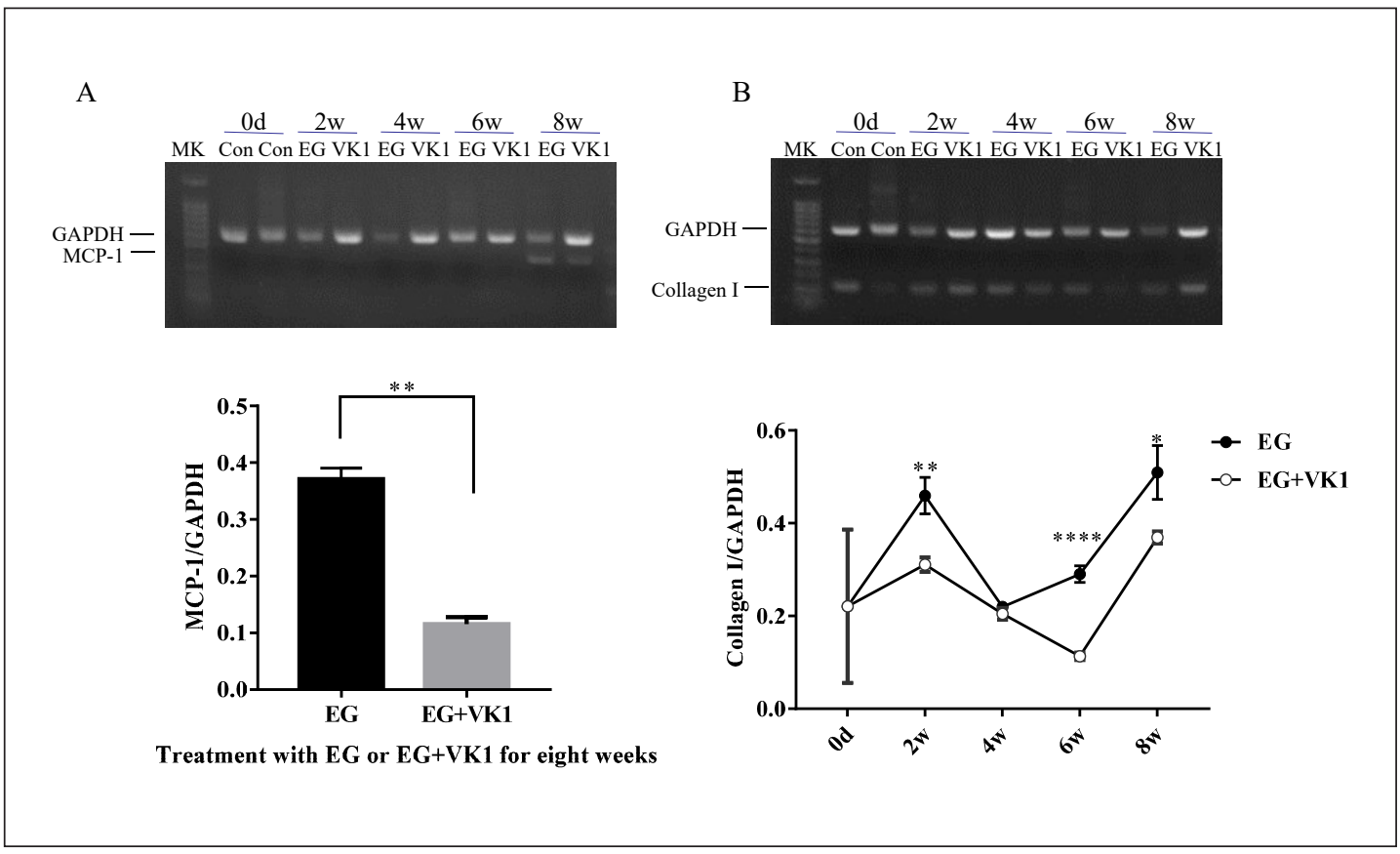

Fig. 2. VK1 protected the kidney from the inflammation and fibrosis induced by EG. The mRNA expressions of MCP-1 (A) and collagen I (B) were measured by semiquantitative PCR. MK represents a 100-bp DNA marker and Con represents controls without treatment. The product lengths of MCP-1 and collagen I were 412 and $123 \mathrm{bp}$, respectively. ${ }^{*} p<0.05,{ }^{* *} p<0.01,{ }^{* * *} p<0.0001 \mathrm{vs}$. the levels of the EG group. EG, ethylene glycol; GAPDH, glyceraldehyde 3-phosphate dehydrogenase; MCP-1, monocyte chemoattractant protein-1; VK1, vitamin K1.

Table 2. Comparison of the crystal formation area (\%) in rat kidneys between the VK1 and the control group

\begin{tabular}{llll}
\hline & Control & VK1 & $p$ value \\
\hline 2nd week & 0.02 & 0 & 0.625 \\
4th week & 0.02 & 0 & 0.625 \\
6th week & 1.22 & 0.61 & $0.028^{*}$ \\
8th week & 2.17 & 0.92 & 0.014 \\
\hline
\end{tabular}

VK1, vitamin K1. * $p<0.05$

ological conditions, including atherosclerosis and renal epithelial cells on exposure to calcium oxalate, phosphate, and uric acid crystals $[16,17]$. Collagen I is the most abundant collagen of the human body and forms large, eosinophilic fibers [18]. There was significantly lower expression of MCP-1 in the 8th week and lower expression of collagen I in the 2nd, 6th, and 8th weeks in the VK1 group compared to the EG group ( $p<0.01$; Fig. 2A). These results suggest that VK1 treatment may protect the kidney from inflammation and fibrosis.

\section{VK1 Decreased Crystal Deposition in HK2 Cells}

To explain why VK1 has the effect of inhibiting renal crystal formation, we detected crystal deposition in HK2 cells, which is a critical step for stone formation. HK2 cells were exposed to COM crystals for 5 min after treatment with warfarin or warfarin and VK1 for $48 \mathrm{~h}$. Warfarin is widely used as a VK antagonist by blocking the VK cycle, resulting in func- 
A

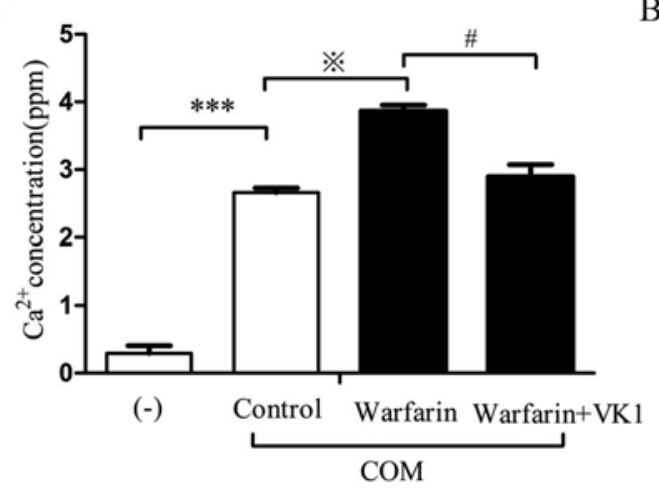

B

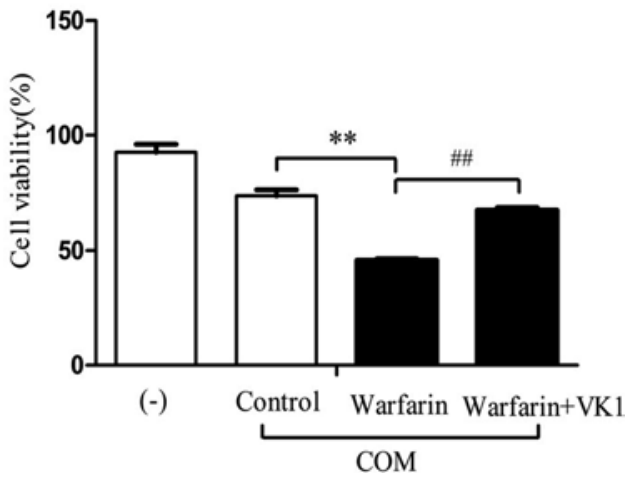

Fig. 3. Investigation of the effect of VK1 on crystal deposition in cells by atomic absorption assay (A) and on cell viability by MTT assay (B). The control group was treated with $100 \mu \mathrm{g} / \mathrm{mL}$ COM crystals, the warfarin group was treated with $100 \mu \mathrm{g} / \mathrm{mL}$ COM crystals and $1 \mathrm{M}$ warfarin, and the warfarin + VK1 group was treated with $100 \mu \mathrm{g} / \mathrm{mL}$ COM crystals, $100 \mu \mathrm{M}$ VK1, and $1 \mathrm{M}$ warfarin. A* $p<0.05$ vs. control; *** $p<0.001$ vs. (-); ${ }^{\#} p<0.05$ vs. warfarin. B ${ }^{* *} p<0.01$ vs. control; ${ }^{\#} p<0.01$ vs. warfarin. COM, calcium oxalate monohydrate; MTT, 3-(4,5-dimethylthiazol-2-yl)-2,5-diphenyltetrazolium bromide; VK1, vitamin K1.

tional VK deficiency. The $\mathrm{Ca}^{2+}$ concentration of the COM crystals adhering to the cells was measured by the atomic absorption method. Quantitative crystal analysis showed that the crystals that adhered to cells treated by warfarin were significantly increased compared to those of the control group. VK1 treatment reversed warfarin's influence and significantly reduced crystal deposition in vitro $(p<0.05$; Fig. $3 \mathrm{~A})$. These results suggest that VK1 treatment could reduce crystal deposition in vitro.

\section{VK1 Protected the Cells from Apoptosis and Injury}

To further elucidate how VK1 plays an inhibiting role in crystal formation under COM crystal exposure, we detected apoptosis and injury among three groups: the control group, the warfarin group, and the warfarin + VK1 group. DAPI, a fluorescent stain, visualizes nuclear DNA in living cells and is used to determine the condensed chromosome to assess apoptosis. The TUNEL assay relies on the presence of nicks in the DNA which can be identified by terminal deoxynucleotidyl transferase, an enzyme that catalyzes the addition of FITC-12dUTPs. Treatment with $1 \mathrm{M}$ warfarin significantly increased the number of apoptotic HK2 cells (Fig. 4) and reduced cell viability (Fig. 3B) compared to the control group, whereas VK1 significantly reduced the number of apoptotic cells and increased cell viability compared to the warfarin group (Fig. 3B, 4). These results suggest that VK1 could protect cells from cell apoptosis and injury induced by COM crystal exposure.

\section{VK Functions through MGP}

To further clarify the mechanism of VK1 in inhibiting crystal formation, we analyzed the target protein of VK1. VK1 is a cofactor in the gamma-carboxylation of glutamate residues in a small group of proteins, including MGP, osteocalcin, Gla-rich protein, and periostin. Of these proteins, MGP is a determined protein of extracellular matrix calcification and is associated with kidney stone formation [19]. We thereby detected MGP. Western blot analysis showed that VK1 induced the upregulation of MGP expression in a time-dependent manner in HK2 cells (Fig. 5A) and increased the expression of MGP at 6 and 8 weeks compared to the EG group (Fig. 5B). 
Research
Kidney

Blood Pressure

Kidney Blood Press Res 2019;44:1392-1403

A

$(-)$
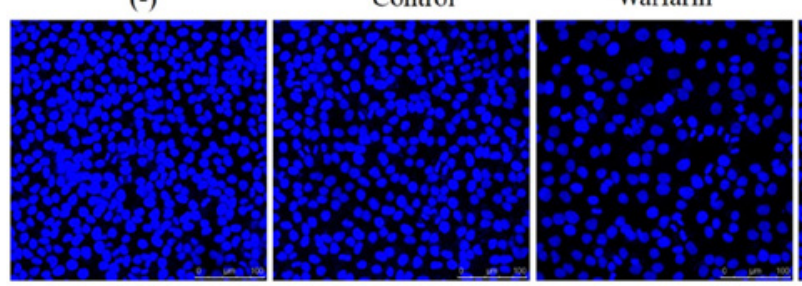

Warfarin+VK

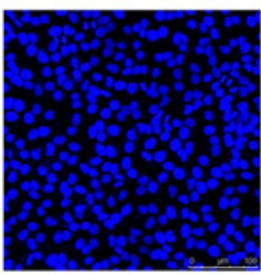

C
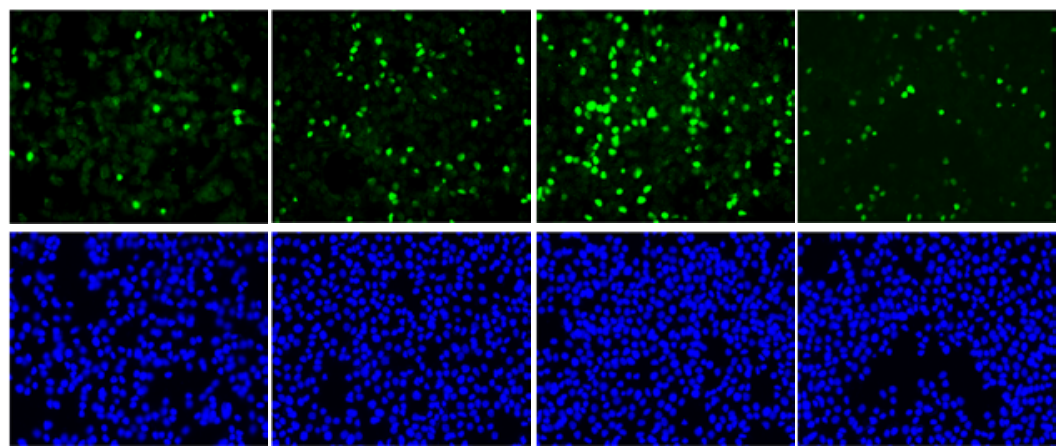

www.karger.com/kbr

Li et al.: Vitamin K1 Inhibits Renal Crystal Formation
$\mathrm{B}$

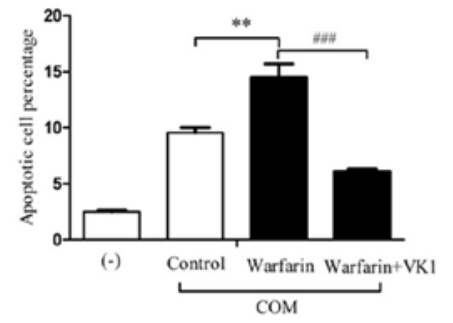

D

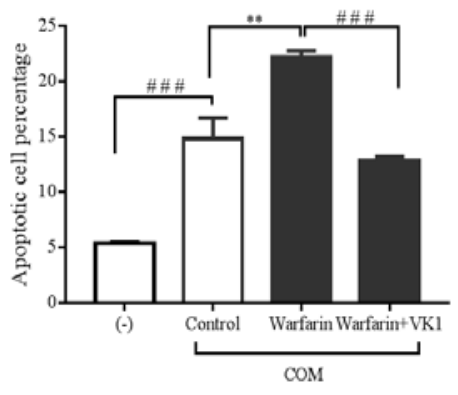

Fig. 4. Investigation of the effect of VK1 on apoptosis by DAPI staining and TUNEL assay. The living cell nuclei were stained in an oval or round shape. A The apoptotic cell nuclei were irregularly shaped. B The percentage of apoptotic cells was calculated. $\mathbf{C}$ The green fluorescence represents apoptotic cells. D The percentage of apoptotic cells was calculated. ${ }^{* *} p<0.01,{ }^{\# \# \#} p<0.001$. COM, calcium oxalate monohydrate; DAPI, $4^{\prime}, 6$-diamidino-2-phenylindole; VK1, vitamin K1.

A

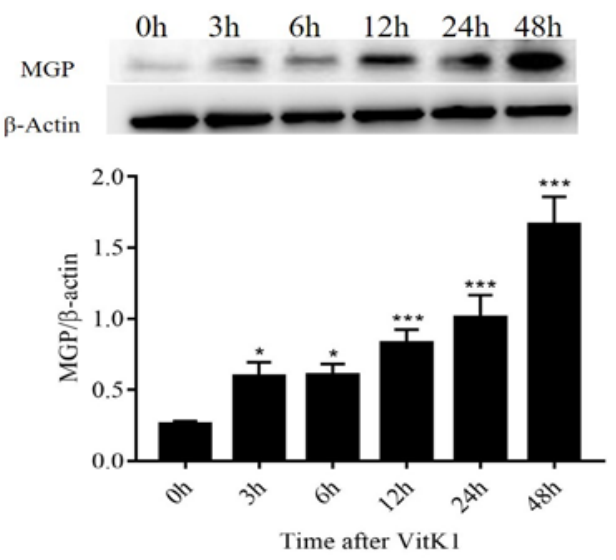

B

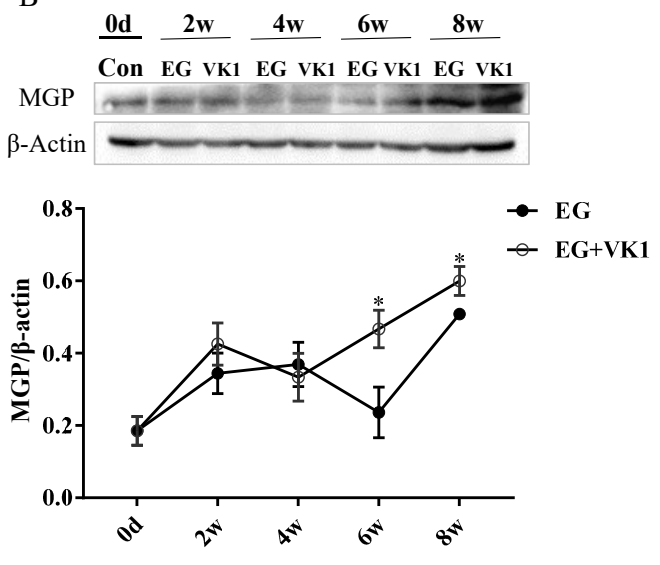

Fig. 5. VK1 treatment increased MGP expression in vivo and in vitro by Western blot analysis. A VK1 increased MGP expression in HK2 cells. ${ }^{*} p<0.05,{ }^{* *} p<0.01,{ }^{* * *} p<0.001$ vs. the level at 0 h. B VK1 increased MGP expression in kidney tissues. ${ }^{*} p<0.05$ vs. the levels of the EG group. EG, ethylene glycol; MGP, matrix Gla protein; VK1, vitamin K1. 


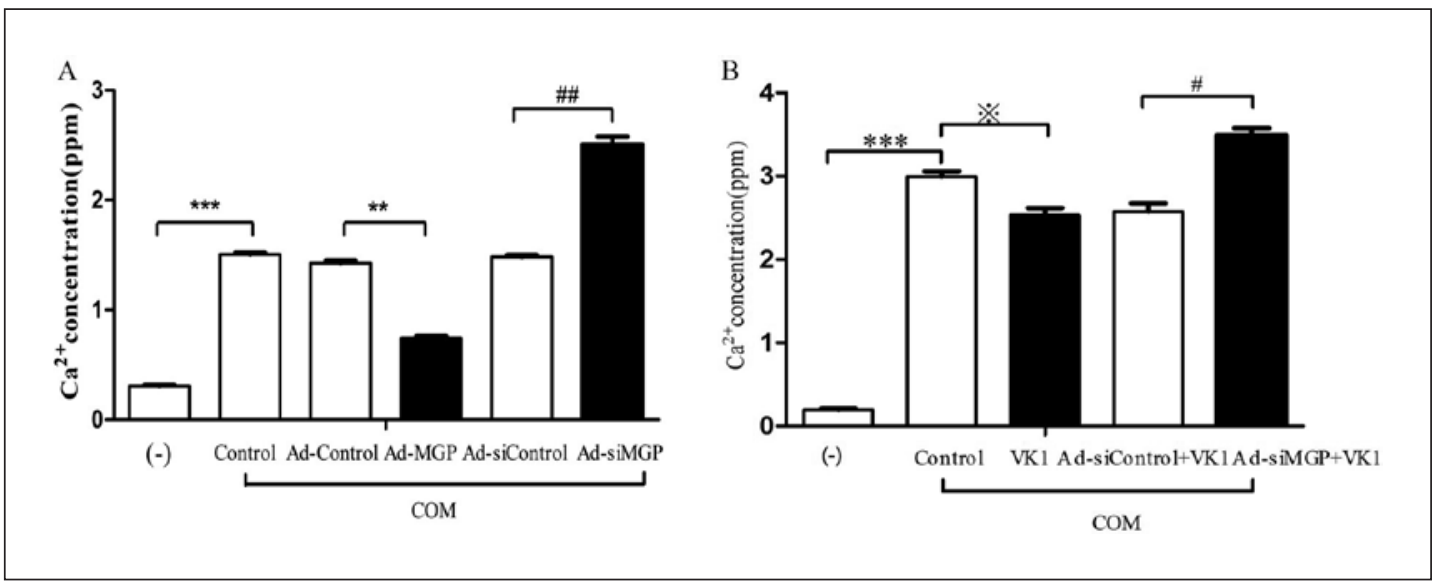

Fig. 6. A Investigation of the effect of MGP on crystal deposition in cells. (-) represents no adenovirus and no COM exposure, Control represents only COM crystal exposure, Ad-Control represents adenovirus without MGP or siMGP, Ad-MGP represents MGP adenovirus, and Ad-siMGP represents siMGP adenovirus. ${ }^{* *} p<0.01$ vs. Ad-Control; ${ }^{* * *} p<0.001$ vs. (-); ${ }^{\# \#} p<0.01$ vs. Ad-siControl. B VK1 function by MGP. ${ }^{*} p<0.05$ vs. control; ${ }^{* * *} p<0.001$ vs. $(-),{ }^{*} p<0.05$ vs. Ad-siControl + VK1. COM, calcium oxalate monohydrate; MGP, matrix Gla protein; VK1, vitamin K1.

To elucidate the role of MGP in crystal formation, we further constructed adenoviruses increasing (Ad-MGP) and reducing MGP expression (Ad-siMGP). The effect of two kinds of adenovirus on the expression of MGP was verified successfully by RT-PCR. Increasing MGP expression (Ad-MGP group) reduced crystal deposition compared to the Ad-Control group, whereas reducing MGP expression (Ad-siMGP group) significantly increased crystal deposition in cells compared to the Ad-siControl group (Fig. 6A), suggesting that MGP significantly affected crystal deposition in vitro.

To prove whether VK1 functions inhibit crystal formation through MGP or itself, an experiment using the adenovirus expressing siMGP was performed among the four groups, including the control group, the VK1 group, and VK1 added adenovirus with control vector (Ad-siControl + VK1) or with siRNA against MGP (Ad-siMGP + VK1) (Fig. 6B). In the Ad-siMGP + VK1 group, the Ad-siMGP treatment significantly abolished the effect of VK1 on the improving crystal deposition compared to Ad-siControl under COM exposure. These results strongly demonstrated that MGP is necessary for VK1 to play a role in crystal deposition in cells.

\section{Discussion}

Prevention of nephrolithiasis is an essential medical topic due to a high incidence of recurrence. In this study, we evaluated the effect of VK1 on preventing crystal formation in vivo and in vitro. We found for the first time that VK1 plays a role in inhibiting crystal formation by decreasing crystal deposition and protecting cells from apoptosis and injury through MGP. Also, VK1 treatment may protect the kidney from inflammation and fibrosis. These findings suggest that VK1 could contribute to the treatment and prevention of nephrolithiasis.

VK is a liposoluble vitamin, including the naturally occurring VK1 and VK2 and the synthetic VK3 and VK4 [20]. VK1 is synthesized by plants and vegetables, whereas VK2 can be endogenously produced in animals or synthesized by intestinal bacteria [20]. VK1 can be converted into VK2 and accumulated in extrahepatic tissues [21]. The limited storage capacity 


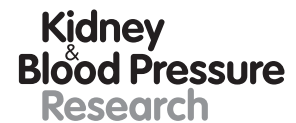

Kidney
Blood Pressure
Research \begin{tabular}{l|l}
\hline Kidney Blood Press Res 2019;44:1392-1403 \\
\hline DOI: 10.1159/000503300 & $\begin{array}{l}\text { @ 2019 The Author(s). Published by S. Karger AG, Basel } \\
\text { www.karger.com/kbr }\end{array}$ \\
\hline
\end{tabular}

Li et al.: Vitamin K1 Inhibits Renal Crystal Formation

of VK in the human body can easily lead to VK deficiency [22]. Warfarin acts as a VKantagonist by blocking the VK cycle, resulting in functional VK deficiency [22, 23]. Extensive calcification was observed in the rat kidney after warfarin treatment [24]. However, the mechanism is still unknown. Here, our in vivo results showed that intake of VK1 notably delayed and reduced crystal formation in the rat kidney. Besides, our in vitro results showed that warfarin-induced VK deficiency led to increased crystal deposition and apoptosis in renal tubular epithelial cells, whereas VK1 treatment could reverse the adverse effect to a large extent. These results suggest that VK1 treatment is a potential prevention and treatment strategy for nephrolithiasis.

MGP, a VK-dependent extracellular matrix protein, is found in bone, cartilage, tooth, and soft tissues such as kidney, lung, and heart in mammals [25]. VK acts as a coenzyme of y-glutamyl carboxylase, transforming undercarboxylated into carboxylated proteins, such as MGP and osteocalcin. MGP is a molecular determinant regulating calcification of the extracellular matrix. MGP has a high affinity for calcium, phosphate, and hydroxyapatite crystals [26]. Luo et al. [27] reported that MGP-deficient mice died from arterial calcification within 8 weeks. Overexpression of MGP might repair vascular calcification [28]. MGP was highly expressed in calcified human atherosclerotic plaques [29]. The serum MGP levels in patients with calcified coronary heart disease are lower than those in subjects without coronary artery disease [30]. Our previous study showed that crystals were more likely to form in renal tubules without MGP expression in vivo [19]. Our present study showed that VK1 treatment continuously increased MGP expression in HK2 cells. Another study by Koos et al. [31] showed that mice administered warfarin or VK antagonists might decrease the expression of MGP in the aorta. We speculated that this might be caused by an unclear positive feedback mechanism that needs further experiments to elucidate. The overexpression of MGP mediated by adenovirus Ad-MGP reduced crystal deposition in cells, whereas downexpression of MGP induced by adenovirus Ad-siMGP significantly increased crystal deposition in cells (Fig. 6A). This finding further clarifies the role of MGP in inhibiting crystal formation in the kidney. VK1 treatment with Ad-siMGP led loss of the inhibiting role of VK1 in crystal deposition in cells, suggesting that VK1 cannot work alone, but must work through MGPs (Fig. 6B). Besides, the observation that functional VK deficiency by warfarin increased crystal deposition in cells indicated that MGP could not work without VK either. These results imply that MGP, a target protein of VK1, is a vital inhibitor not only in the calcification of vessel and bone, but also in kidney stone formation.

In the current study, two limitations should be mentioned. First, we did not detect the activity of MGP due to lack of available carboxylation antibody. It is not confirmed whether VK1 also leads to increased activity of MGP. Second, we only focused on MPG, a target protein of VK1, due to the importance of its role in kidney stones and vascular calcification. We do not rule out that other target proteins of VK, such as osteocalcin, periostin, and GRP, that are also involved in the inhibition of stone formation. Based on our results, VK1 plays a role in inhibiting kidney stone formation, at least primarily through MGP. Further studies are required to clarify these limitations.

In summary, our study showed the VK1 could inhibit the formation of renal crystals in vivo and in vitro. Moreover, we also demonstrated that VK1 functions mainly through MGP to reduce crystal deposition in cells and protect renal tubular epithelial cells from apoptosis and injury. VK1 treatment may become a potential strategy for the prevention and treatment of kidney stones. 


\section{Statement of Ethics}

The experiment was reviewed and approved by the Shenyang Medical College Animal Committee.

\section{Disclosure Statement}

There are no conflicts of interest.

\section{Funding Sources}

This study was supported by grants from the National Natural Science Foundation of China (No. 81570632), the Project from the Education Department of Liaoning Province (No. LR2016063 and LFW201701), the Project from the Science and Technology Department of Liaoning Province (No. 2019JH8/10300057), and the Science and Technology Bureau of Shenyang (No. RC170272 and 18-007-0-02).

\section{Author Contributions}

B. Gao, X. Lu, and T. Yasui designed the research. Y. Li and X. Lu analyzed the data. B. Yang, Y. Li, J. Mao, S. Jiang, D. Yu, J. Pan, and T. Cai performed the research. Y. Li and X. Lu wrote the paper.

\section{References}

1 Pak CY. Kidney stones. Lancet. 1998 Jun;351(9118):1797-801.

2 Bushinsky DA. Recurrent hypercalciuric nephrolithiasis - does diet help? N Engl J Med. 2002 Jan;346(2):124-5.

3 Martini LA, Wood RJ. Should dietary calcium and protein be restricted in patients with nephrolithiasis? Nutr Rev. 2000 Apr;58(4):111-7.

4 Asplin JR. Hyperoxaluric calcium nephrolithiasis. Endocrinol Metab Clin North Am. 2002 Dec;31(4):927-49.

5 Worcester E, Parks JH, Josephson MA, Thisted RA, Coe FL. Causes and consequences of kidney loss in patients with nephrolithiasis. Kidney Int. 2003 Dec;64(6):2204-13.

6 Jungers P, Joly D, Barbey F, Choukroun G, Daudon M. ESRD caused by nephrolithiasis: prevalence, mechanisms, and prevention. Am J Kidney Dis. 2004 Nov;44(5):799-805.

7 Gao B, Yasui T, Itoh Y, Li Z, Okada A, Tozawa K, et al. Association of osteopontin gene haplotypes with nephrolithiasis. Kidney Int. 2007 Sep; 72(5):592-8.

8 Icer MA, Gezmen-Karadag M. The multiple functions and mechanisms of osteopontin. Clin Biochem. 2018 Sep; 59:17-24.

9 Gao B, Yasui T, Lu X, Zhou H, Liu J, Liu P, et al. Matrix Gla protein expression in NRK-52E cells exposed to oxalate and calcium oxalate monohydrate crystals. Urol Int. 2010;85(2):237-41.

10 Zaragatski E, Grommes J, Schurgers LJ, Langer S, Kennes L, Tamm M, et al. Vitamin K antagonism aggravates chronic kidney disease-induced neointimal hyperplasia and calcification in arterialized veins: role of vitamin K treatment? Kidney Int. 2016 Mar;89(3):601-11.

11 Schurgers LJ. Vitamin K: key vitamin in controlling vascular calcification in chronic kidney disease. Kidney Int. 2013 May;83(5):782-4.

12 Harshman SG, Shea MK. The Role of Vitamin K in Chronic Aging Diseases: Inflammation, Cardiovascular Disease, and Osteoarthritis. Curr Nutr Rep. 2016 Jun;5(2):90-8.

13 van Ballegooijen AJ, Beulens JW. The Role of Vitamin K Status in Cardiovascular Health: Evidence from Observational and Clinical Studies. Curr Nutr Rep. 2017;6(3):197-205.

14 Price PA, Kaneda Y. Vitamin K counteracts the effect of warfarin in liver but not in bone. Thromb Res. 1987 Apr;46(1):121-31.

15 Markussen MD, Heiberg AC, Nielsen R, Leirs H. Vitamin K requirement in Danish anticoagulant-resistant Norway rats (Rattus norvegicus). Pest Manag Sci. 2003 Aug;59(8):913-20. 
16 Umekawa T, Chegini N, Khan SR. Increased expression of monocyte chemoattractant protein-1 (MCP-1) by renal epithelial cells in culture on exposure to calcium oxalate, phosphate and uric acid crystals. Nephrol Dial Transplant. 2003 Apr;18(4):664-9.

17 Umekawa T, Chegini N, Khan SR. Oxalate ions and calcium oxalate crystals stimulate MCP-1 expression by renal epithelial cells. Kidney Int. 2002 Jan;61(1):105-12.

18 Zhang D, Sun L, Xian W, Liu F, Ling G, Xiao L, et al. Low-dose paclitaxel ameliorates renal fibrosis in rat UUO model by inhibition of TGF-beta/Smad activity. Lab Invest. 2010 Mar; 90(3):436-47.

19 Lu X, Gao B, Yasui T, Li Y, Liu T, Mao X, et al. Matrix Gla protein is involved in crystal formation in kidney of hyperoxaluric rats. Kidney Blood Press Res. 2013;37(1):15-23.

20 Zittermann A. Effects of vitamin K on calcium and bone metabolism. Curr Opin Clin Nutr Metab Care. 2001 Nov; 4(6):483-7.

21 Okano T, Shimomura Y, Yamane M, Suhara Y, Kamao M, Sugiura M, et al. Conversion of phylloquinone (Vitamin K1) into menaquinone-4 (Vitamin K2) in mice: two possible routes for menaquinone-4 accumulation in cerebra of mice. J Biol Chem. 2008 Apr;283(17):11270-9.

22 Fusaro M, Mereu MC, Aghi A, Iervasi G, Gallieni M. Vitamin K and bone. Clin Cases Miner Bone Metab. 2017 May-Aug;14(2):200-6.

23 Gallieni M, Fusaro M. Vitamin K and cardiovascular calcification in CKD: is patient supplementation on the horizon? Kidney Int. 2014 Aug;86(2):232-4.

24 Schurgers LJ, Spronk HM, Soute BA, Schiffers PM, DeMey JG, Vermeer C. Regression of warfarin-induced medial elastocalcinosis by high intake of vitamin K in rats. Blood. 2007 Apr;109(7):2823-31.

25 Fraser JD, Price PA. Lung, heart, and kidney express high levels of mRNA for the vitamin K-dependent matrix Gla protein. Implications for the possible functions of matrix Gla protein and for the tissue distribution of the gamma-carboxylase. J Biol Chem. 1988 Aug;263(23):11033-6.

26 Price PA. Gla-containing proteins of bone. Connect Tissue Res. 1989;21(1-4):51-7; discussion 57-60.

27 Luo G, Ducy P, McKee MD, Pinero GJ, Loyer E, Behringer RR, et al. Spontaneous calcification of arteries and cartilage in mice lacking matrix GLA protein. Nature. 1997 Mar;386(6620):78-81.

28 Murshed M, Schinke T, McKee MD, Karsenty G. Extracellular matrix mineralization is regulated locally; different roles of two gla-containing proteins. J Cell Biol. 2004 Jun;165(5):625-30.

29 Proudfoot D, Skepper JN, Shanahan CM, Weissberg PL. Calcification of human vascular cells in vitro is correlated with high levels of matrix Gla protein and low levels of osteopontin expression. Arterioscler Thromb Vasc Biol. 1998 Mar;18(3):379-88.

30 O'Donnell CJ, Shea MK, Price PA, Gagnon DR, Wilson PW, Larson MG, et al. Matrix Gla protein is associated with risk factors for atherosclerosis but not with coronary artery calcification. Arterioscler Thromb Vasc Biol. 2006 Dec;26(12):2769-74.

31 Koos R, Krueger T, Westenfeld R, Kühl HP, Brandenburg V, Mahnken AH, et al. Relation of circulating Matrix Gla-Protein and anticoagulation status in patients with aortic valve calcification. Thromb Haemost. 2009 Apr; 101(4):706-13. 